\title{
Is autosomal dominant polycystic kidney disease an early sweet disease?
}

\author{
Angélique Dachy ${ }^{1,2,3} \cdot$ Jean-Paul Decuypere ${ }^{1} \cdot$ Rudi Vennekens $^{4} \cdot$ François Jouret $^{3,5} \cdot$ Djalila Mekahli $^{1,6}$ (I)
}

Received: 6 September 2021 / Revised: 9 December 2021 / Accepted: 10 December 2021

(c) The Author(s), under exclusive licence to International Pediatric Nephrology Association 2022

\begin{abstract}
The clinical course of autosomal dominant polycystic kidney disease (ADPKD) starts in childhood. Evidence of the beneficial impact of early nephron-protective strategies and lifestyle modifications on ADPKD prognosis is accumulating. Recent studies have described the association of overweight and obesity with rapid disease progression in adults with ADPKD. Moreover, defective glucose metabolism and metabolic reprogramming have been reported in distinct ADPKD models highlighting these pathways as potential therapeutic targets in ADPKD. Several "metabolic" approaches are currently under evaluation in adults, including ketogenic diet, food restriction, and metformin therapy. No data are available on the impact of these approaches in childhood thus far. Yet, according to World Health Organization (WHO), we are currently facing a childhood obesity crisis with an increased prevalence of overweight/obesity in the pediatric population associated with a cardio-metabolic risk profile. The present review summarizes the knowledge about the role of glucose metabolism in the pathophysiology of ADPKD and underscores the possible harm of overweight and obesity in ADPKD especially in terms of long-term cardiovascular outcomes and renal prognosis.
\end{abstract}

Keywords Autosomal dominant polycystic kidney disease $\cdot$ Glucose $\cdot$ Insulin $\cdot$ Obesity $\cdot$ Overweight $\cdot$ Children

\begin{tabular}{ll}
\multicolumn{2}{l}{ Abbreviations } \\
ADPKD & $\begin{array}{l}\text { Autosomal dominant polycystic kidney } \\
\text { disease }\end{array}$ \\
& AMP-activated protein kinase \\
AMPK & Body mass index \\
BMI & Blood pressure \\
BP & Chronic kidney disease \\
CKD & 2-Deoxy-D-glucose
\end{tabular}

Djalila Mekahli

djalila.mekahli@uzleuven.be

1 PKD Research Group, GPURE, Department of Development and Regeneration, KU Leuven, Leuven, Belgium

2 Department of Pediatrics, ULiège Academic Hospital, Liège, Belgium

3 Laboratory of Translational Research in Nephrology (LTRN), GIGA Cardiovascular Sciences, ULiège, Liège, Belgium

4 Laboratory of Ion Channel Research, Department of Cellular and Molecular Medicine, VIB Center for Brain and Disease Research, KU Leuven, Leuven, Belgium

5 Division of Nephrology, Department of Internal Medicine, ULiège Academic Hospital, Liège, Belgium

6 Department of Pediatric Nephrology, University Hospitals Leuven, Herestraat 49, B-3000 Leuven, Belgium

$\begin{array}{ll}\text { eGFR } & \text { Estimated glomerular filtration rate } \\ \text { Han:SPRD } & \text { Harlan Sprague-Dawley } \\ \text { mTORC } & \begin{array}{l}\text { Mammalian/mechanistic target of rapamycin } \\ \text { complex }\end{array} \\ \text { PC1 } & \text { Polycystin-1 } \\ \text { PT } & \text { Proximal tubule } \\ \text { SGLT } & \text { Sodium-glucose cotransporter } \\ \text { TKV } & \text { Total kidney volume } \\ \text { WHO } & \text { World Health Organization }\end{array}$

\section{Introduction}

Recent advances in the understanding of the energetic cellular processes used by cyst-lining cells have highlighted glucose metabolic rewiring as a core element of ADPKD pathogenesis [1]. The "Warburg effect," which corresponds to a central metabolic alteration characterized by a preferential aerobic glycolysis, has been identified as a turning point in cell metabolic reprogramming [2-4]. The administration of the non-metabolizable glucose analogue 2-deoxy-D-glucose (2-DG) has been shown in vitro and in vivo to slow down cyst formation [2, 4]. Hence, several dietary and pharmacological interventions targeting glucose metabolism have emerged as 
potential new therapeutic targets in ADPKD. These include daily caloric restriction [5, 6], time-restricted feeding [7], the ketogenic diet [7] as well as metformin-based therapy targeting the AMP-activated protein kinase (AMPK) pathway [8-11] and the selective inhibition of sodium-glucose cotransporters [12-15]. Additionally, it seems that ADPKD causes systemic perturbances of carbohydrate metabolism. Indeed, defects in insulin secretion and insulin resistance have both been reported in adult patients with ADPKD with preserved kidney function $[16,17]$.

Furthermore, several overlapping features have been identified between obesity and ADPKD [3]. Nowak et al. demonstrated that overweight and obesity were correlated with kidney growth and estimated glomerular filtration rate (eGFR) decline in young adults with ADPKD [18], while glucose metabolism, quantified based on metabolomics data, was significantly different in children with ADPKD compared to healthy controls [19]. Furthermore, obesity and insulin resistance have been associated even in the general population, with the occurrence and progression of chronic kidney disease (CKD) in both children and adults [20-23]. According to the World Health Organization (WHO), we are currently facing a childhood obesity crisis with an increased prevalence of overweight/obesity in the pediatric population. Such a rise in the prevalence of obesity has been particularly observed in school-aged children and adolescents. In a WHO European study, severe obesity was affecting almost 400,000 of the 13.7 million children aged 6 to 9 years living in the 21 participating countries [24]. The pediatric community is very active in tackling this phenomenon with more diet and lifestyle recommendations.

Obesity in childhood is associated with short- but also longterm cardiovascular and metabolic risk profiles through the development of hypertension [25], impaired glucose tolerance [26], type 2 diabetes [27], dyslipidemia [28], and early atherosclerosis [29]. Besides, compared to overweight children, severely obese children have an immediate much worse cardiometabolic risk profile [24].

Based on the current knowledge, exploring the glucose metabolism in early ADPKD, and moreover investigating the role of screening and early management of overweight/ obesity are of particular interest to prevent ADPKD progression and long-term cardiovascular complications. Here, we summarize the literature about glucose metabolism and ADPKD, and we propose hypotheses about the overlapping features between ADPKD, obesity, and its associated comorbidities, with a special focus on pediatric patients.

\section{Clinical manifestations of metabolic disturbances in adult patients with ADPKD}

Both overweight and obesity are associated with increased cardiovascular disease mortality and morbidity. A prospective analysis of 5,209 adults aged 35 to 75 years and followed up to 44 years in the Framingham Heart Study revealed that overweight and obese patients have a significant increased risk of developing hypertension, type 2 diabetes, and hypercholesterolemia. In this study, the age-adjusted relative risk for new cardiovascular events and mortality was increased from 1.5 to 1.7 in overweight patients and from 2.2 to 2.6 in obese patients [30]. Insulin resistance, which is the earliest carbohydrate impairment related to obesity, has also been significantly and independently associated with a higher cardiovascular risk [31]. Moreover, obesity has a direct impact on the development of CKD. In healthy adults, higher BMI was associated with the development of proteinuria and progressive eGFR decline [23], while it was associated with faster decline in kidney function in individuals with pre-existing CKD [20].

The prevalence of obesity is currently rising in patients with ADPKD, as in the general population. In the HALTPKD study including 441 adult non-diabetic participants with ADPKD showed that $60 \%$ of patients were overweight or obese [18]. In this study, non-diabetic adult patients with preserved kidney function (eGFR $>60 \mathrm{ml} /$ $\min / 1.73 \mathrm{~m}^{2}$ ) were categorized according to their BMI and followed for 5 years to assess changes in TKV and eGFR. The annual percent change in TKV was positively correlated with increasing BMI category. Obese patients displayed an annual percent increase in TKV 50\% higher than normal weight participants, even after correction of weight related to kidney and liver size. Obesity was also associated with a faster eGFR decline compared to the normal weight group. For every 5-unit increase in BMI, eGFR declined by $-0.01(-0.96 ; 0.93) \mathrm{ml} / \mathrm{min} / 1.73 \mathrm{~m}^{2}$ at month $24,-1.60(-3.02 ;-0.19) \mathrm{ml} / \mathrm{min} / 1.73 \mathrm{~m}^{2}$ at month 48 , and $-1.71(-3.17 ;-0.24) \mathrm{ml} / \mathrm{min} / 1.73 \mathrm{~m}^{2}$ at month 60 [18]. These findings were confirmed in a more recent post hoc analysis of the TEMPO 3:4 trial [32], evaluating whether overweight and obesity could have an impact on the efficacy of tolvaptan. Overweight and obesity were also strongly and independently associated with ADPKD progression, but increased BMI did not seem to affect tolvaptan efficacy. The exact mechanisms linking obesityassociated metabolic changes with cystogenesis remain unclear. 
Insulin resistance has been previously reported in small cohorts of adults with ADPKD but with conflicting results. Lower insulin sensitivity with associated hyperinsulinemia was reported in adult ADPKD patients with normal kidney function [33-35]. In a study comparing the insulin sensitivity of 49 adult ADPKD patients with preserved kidney function versus healthy controls during an oral glucose tolerance test, impaired insulin secretion was reported in ADPKD patients with no significant differences in insulin sensitivity between groups [17]. However, other studies were unable to validate these results $[16,36]$. It should be acknowledged that these studies were performed in small cohorts of ADPKD patients, with distinct methodologies and endpoints (Table 1). Furthermore, no studies have quantified the insulin sensitivity in ADPKD patients using the hyperinsulinemic-euglycemic clamp standard method [37]. ADPKD is a well-known independent risk factor for new-onset diabetes after transplantation in adults (Table 1) [38-40]. Furthermore, in a retrospective cohort study comparing pre-kidney transplant patients with both ADPKD and type 2 diabetes versus age- and gender-matched nondiabetic patients with ADPKD, diabetic patients displayed higher body mass index (BMI) and greater kidney volumes than those with no diabetes [41].

Cardiovascular diseases represent the most common cause of mortality and morbidity in patients with ADPKD [42]. Main contributors of this increased cardiovascular risk have been identified in ADPKD patients, including age at CKD initiation, hypertension, diabetes, obesity, and dyslipidemia [43]. However, there are limited data in the literature regarding cardiovascular risk factors in ADPKD patients. Total kidney volume was associated with a higher cardiovascular risk profile in normotensive ADPKD patients [44]. A cross-sectional study found higher inflammatory indexes, greater insulin resistance, and endothelial dysfunction in 24 ADPKD patients versus 24 age- and sex-matched controls [45]. Only one large prospective cohort study evaluated the prevalence of cardiovascular risk factors and the impact of their management in ADPKD patients with CKD compared to non-CKD patients and patients with CKD from

Table 1 Clinical studies evaluating the metabolic profile of ADPKD patients

\begin{tabular}{|c|c|c|}
\hline Study & Population/intervention & Findings \\
\hline \multicolumn{3}{|c|}{ Insulin resistance positive } \\
\hline Sorof et al. [25] & $\begin{array}{l}15 \text { ADPKD with eGFR }>90 \mathrm{ml} / \mathrm{min} / 1.73 \mathrm{~m}^{2} \text { vs. } 20 \text { age- } \\
\text { and sex-matched healthy controls }\end{array}$ & $\begin{array}{l}\cdot \downarrow \text { insulin sensitivity in ADPKD } \\
\uparrow \text { insulin concentration in ADPKD } \\
\cdot \text { Normal } \beta \text {-cell function in ADPKD }\end{array}$ \\
\hline Sinha et al. [26] & $\begin{array}{l}21 \text { ADPKD with different stages of kidney failure vs. } 16 \\
\text { age- and sex-matched healthy controls }\end{array}$ & $\begin{array}{l}\downarrow \downarrow \text { insulin sensitivity in all vs. in controls } \\
\cdot \downarrow \text { early insulin secretion in all vs. controls } \\
\cdot \text { Insulin resistance in ADPKD }\end{array}$ \\
\hline Shaw [27] & $\begin{array}{l}22 \text { ADPKD with eGFR }>60 \mathrm{ml} / \mathrm{min} / 1.73 \mathrm{~m}^{2} \text { vs. } 19 \\
\text { healthy controls }\end{array}$ & $\cdot \uparrow \mathrm{HOMA}-\mathrm{IR}$ in ADPKD \\
\hline Skinner et al. [28] & $\begin{array}{l}49 \text { ADPKD with normal kidney function vs. } 50 \text { healthy } \\
\text { controls }\end{array}$ & $\begin{array}{l}\downarrow \text { insulin concentration at } 30 \mathrm{~min} \text { of the OGTT in } \\
\text { ADPKD } \\
.4 \text { indexes of } \beta \text {-cell function } \downarrow \text { in ADPKD } \\
\text {. No differences in HOMA-IR }\end{array}$ \\
\hline \multicolumn{3}{|c|}{ Insulin resistance negative } \\
\hline Baker et al. [29] & $\begin{array}{l}50 \text { hypertensive ADPKD with eGFR }>60 \mathrm{ml} / \mathrm{min} / 1.73 \\
\mathrm{~m}^{2} \\
52 \text { hypertensive ADPKD with eGFR } 25-60 \mathrm{ml} / \mathrm{min} / 1.73 \\
\mathrm{~m}^{2} \\
42 \text { normotensive ADPKD with eGFR }>60 \mathrm{ml} / \mathrm{min} / 1.73 \\
\mathrm{~m}^{2} \\
50 \text { healthy controls }\end{array}$ & $\begin{array}{l}\text { No differences in insulin concentration and HOMA-IR in } \\
\text { ADPKD vs. controls }\end{array}$ \\
\hline Chang et al. [9] & 189 ADPKD (30\% kidney transplant recipients) & $\begin{array}{l}\text {-No differences in the mean fasting glucose levels } \\
\text { between non-transplanted and transplanted ADPKD } \\
\text { patients }\end{array}$ \\
\hline \multicolumn{3}{|c|}{ New-onset diabetes after transplantation } \\
\hline Nowak et al. [32] & $\begin{array}{l}135 \text { ADPKD vs. } 135 \text { matched controls vs. } 162 \text { non- } \\
\text { matched cohort }\end{array}$ & $\begin{array}{l}17 \% \text { NODAT in ADPKD vs. } 7.4 \% \text { in matched controls } \\
\text { vs. } 8 \% \text { in non-matched controls }\end{array}$ \\
\hline Wilson et al. [30] & 429 kidney allografts in non-diabetic patients & $\cdot 13.4 \%$ NODAT in ADPKD vs. $5.2 \%$ in non-ADPKD \\
\hline Yajnik et al. [31] & 18 ADPKD vs. 112 non-ADPKD & $\begin{array}{l}\text { 55.6\% NODAT in ADPKD vs. } 28 \% \text { NODAT in non- } \\
\text { ADPKD }\end{array}$ \\
\hline
\end{tabular}

$A D P K D$, autosomal dominant polycystic kidney disease; $e G F R$, estimated glomerular filtration rate; HOMA-IR, homeostasis model assessment; $O G T T$, oral glucose tolerance test; NODAT, new-onset diabetes after transplantation 
other causes [46]. In this recent study, 1751 patients (132 ADPKD, 1121 with CKD from other causes, and 498 nonCKD patients) were followed for 4 years. ADPKD patients with CKD had an intermediate rate of atheromatous plaque compared to CKD of other causes, showed worse achievements of blood pressure targets but had lower cardiovascular events. However, the duration of follow-up was limited and ADPKD patients with CKD were younger than patients with other causes of CKD. Compared to non-CKD controls, ADPKD patients had increased rate of hypertension and dyslipidemia, but no differences were found in in the rate of atheromatous plaque. Similarly, there were no differences in the rate of overweight and obesity between both groups. Further studies are needed to determine the impact of metabolic disturbances on cardiovascular outcomes in ADPKD patients.

More recently, a post hoc analysis of the HALT-PKD trial revealed that obesity in adults was an independent risk factor for back pain in both early and late stage ADPKD [47]. In this study, moderate weight loss was associated with reduced worsening of back pain over time compared to the reference group with stable weight. As chronic and/or back pain is an important and early burden in ADPKD patients [48], management of obesity early in life could have an impact on the future quality of life of ADPKD patients.

\section{The influence of obesity and metabolic disturbances in the ADPKD pediatric population}

During the last decades, the prevalence of overweight and obesity in childhood has increased worldwide [49]. Multiple factors contribute to childhood obesity, including genetic background, dietary factors (high fat and excess caloric intake), and physical inactivity. Obesity is associated with decreased insulin sensitivity, dyslipidemia, systemic inflammation, and hypertension leading to increased cardiovascular risk, even in children [50].

Increased fasting blood glucose levels, impaired glucose tolerance, and insulin resistance are highly prevalent in children and adolescents with obesity [26]. Obesity and insulin resistance have been related with adverse outcomes in CKD progression in both adults and children [21-23]. Both comorbidities are known to promote glomerular hyperfiltration, which was observed in $\sim 20 \%$ of ADPKD children and associated with a faster decline in kidney function and a faster increase in kidney volume [51-53]. Insulin resistance was identified as an independent risk factor for CKD progression resulting in hyperfiltration, impaired nitric oxidedependent vascular relaxation, increased tissue inflammation, and fibrosis [51]. The inflammatory state related to childhood obesity could also affect ADPKD disease progression as oxidative stress was identified as a factor stimulating cystogenesis [54].

Children with obesity are also at increased risk of hypertension [55]. The prevalence of primary hypertension has reached 20 to $26 \%$ among overweight and obese children [56]. The severity of pediatric obesity has also been linked to non-dipping nocturnal blood pressure (BP), and obesity-related metabolic abnormalities were associated with both severity of hypertension and the risk of organ damage [55]. In a meta-analysis, $20 \%$ of children with ADPKD had hypertension (14 studies including over 900 patients, 95\% CI 15-27\%) [57]. Substantial proportions of isolated nocturnal hypertension (18\%) and nocturnal non-dipping profile (52\%) were identified in a cohort study of 310 children with ADPKD who underwent a 24-h ambulatory BP monitoring [58]. In this cohort, no analyses were made on the BMI. Importantly, ADPKD children with blood pressure $>75$ th percentile had a greater annual increase in kidney volume compared to their normotensive pairs [59]. Moreover, hypertension in childhood ADPKD was also accompanied by increased left ventricular mass index [60].

Very little data are available concerning metabolic abnormalities in children with ADPKD. Only one study has explored the metabolomic profile of 58 children and young patients with ADPKD with a mean age of 16 years. Plasma samples from both ADPKD and healthy controls were collected at baseline and during 3 years for metabolomic analyses to evaluate differences in metabolomic profile between both groups and changes over time. Oxidative stress, endothelial dysfunction, inflammation, and immune responses were the most affected signaling pathways. Amino acid metabolism, glucose metabolism, and fatty acid metabolism were identified as metabolic turn points to account for the metabolic differences between healthy and ADPKD children. Overall, in this study, several glycolysis intermediates were positively correlated with ADPKD disease progression [19]. Correspondingly, inflammation and central carbon metabolism were also reported as main altered processes in a metabolomic study comparing obese children with insulin resistance versus normal insulin sensitivity [61]. Inflammation, oxidative stress, and endothelial dysfunction are hallmarks of both ADPKD and obesity [3, 54, 62] as well as altered mammalian/ mechanistic target of rapamycin complex (mTORC) and AMPK signaling pathways [3].

To date, no studies have evaluated the insulin sensitivity profile of young ADPKD patients. Also, no studies have explored the impact of obesity on ADPKD outcomes in young patients. However, childhood obesity might further increase the risk of hypertension, type 2 diabetes, and subsequent loss of kidney function (Fig. 1). 
Fig. 1 Overlapping features between obesity and insulin resistance ADPKD disease progression. ADPKD, autosomal dominant polycystic kidney disease; AMPK, AMP-activated protein kinase; BMI, body mass index; CKD, chronic kidney disease; $\mathrm{CV}$, cardiovascular; $\mathrm{GH}$, glomerular hyperfiltration; GLUT2/5, glucose transporter 2/5; HTN, hypertension; mTOR, mammalian/mechanistic target of rapamycin; PC, polycystin; OS, oxidative stress; PT, proximal tubular; SGLT2, sodium-glucose cotransporter 2. (-), no risk; (+), at risk; $(+)$ ?, potentially at risk? (literature data insufficient to conclude); $+(+)$ ?, potentially higher risk (literature data insufficient to conclude); $( \pm)$, possibly at risk, depending on patients; $( \pm)$ ?, possibly higher risk, depending on patients (literature data insufficient to conclude)
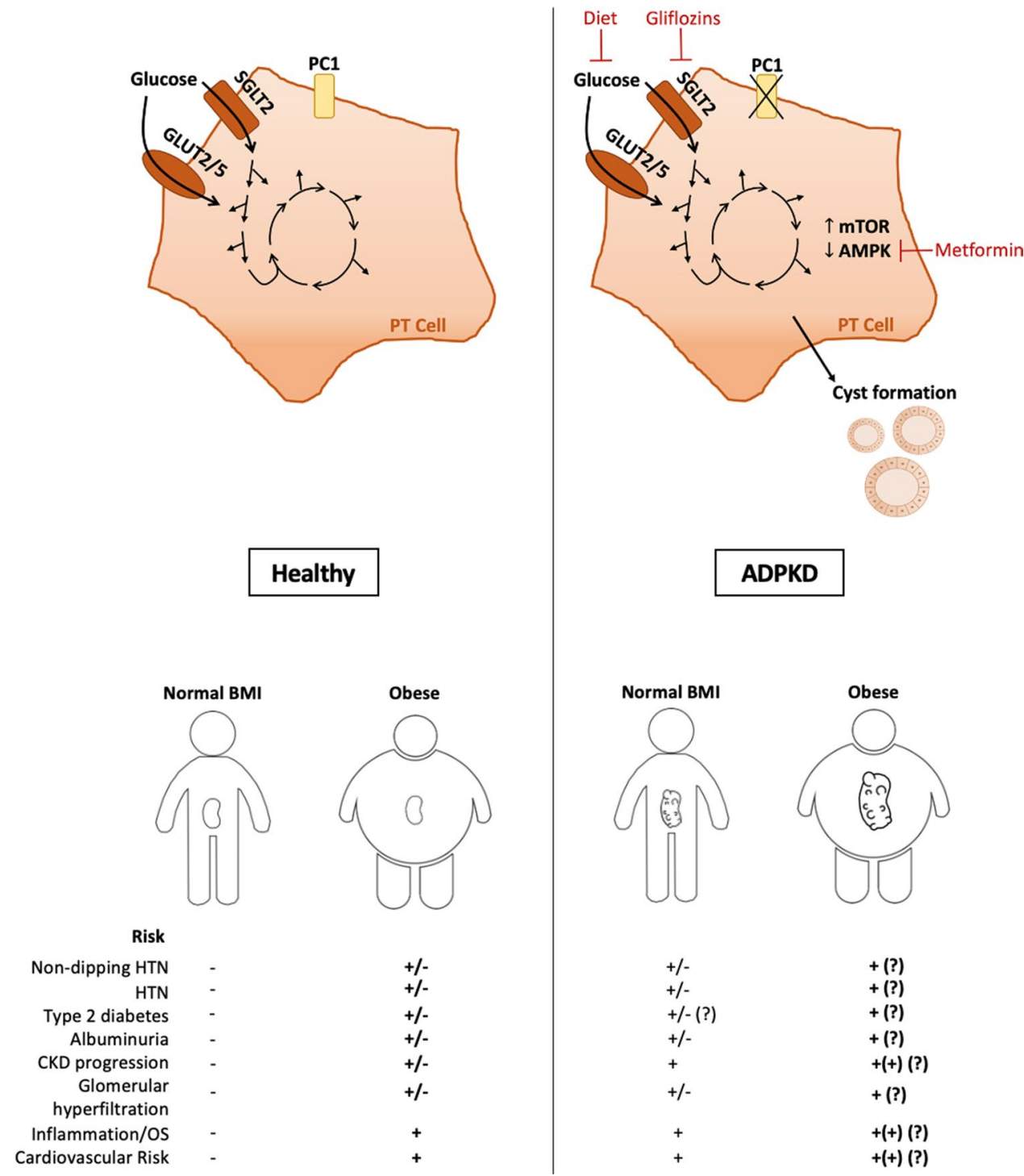

\section{Pivotal role of glucose metabolism in the pathophysiology of ADPKD}

The impairment of carbohydrate metabolism has been highlighted as a key feature and an important disease modulator in ADPKD. In vitro, aberrant aerobic glycolysis prevailed in polycystin-1 (PC1)-deficient epithelial cells derived from mouse embryonic fibroblasts and was associated with decreased oxidative phosphorylation [2]. In vivo analysis of ${ }^{13} \mathrm{C}$-glucose tracer in kidneys of a murine model of PKD has highlighted an increased ${ }^{13} \mathrm{C}$-glucose uptake and conversion to ${ }^{13} \mathrm{C}$-lactate compared to non-cystic control kidneys. In this study, gene expression profiling of both gluconeogenesis and glycolysis pathways in human ADPKD kidneys revealed an upregulation of key glycolytic genes in kidney cysts compared to normal tissue [2]. This altered glucose metabolism in $P K D 1$-deficient cells was correlated with decreased phosphorylation of AMPK and enhanced activity of the mTORC1 [2]. In addition, glucose starvation for 12 to $48 \mathrm{~h}$ in these PKDI-deficient cells resulted in increased proliferation, decreased apoptosis, and altered autophagy response. Furthermore, the administration of a non-metabolizable glucose analogue 2-DG slows down cyst formation both in vitro and in vivo [2, 63, 64]. Metabolomic and transcriptomic profiling of $P K D 1$-deficient mouse tissues identified a profound metabolic shift occurring in ADPKD characterized by increased glycolysis, glutaminolysis, and reduced tricarboxylic acid cycle [4]. On a physiological level, the cell response to changes in glucose availability depends on mTORC1, which is a central player in the glucose-sensing cell response via AMPK in order to adapt energy-consuming protein synthesis to the amount of available glucose [65]. Finally, PC-1 has been involved in various stages of glucose homeostasis as a stimulator of insulin receptor gene transcription [66] and as a promoter of glucose-stimulated insulin secretion in mouse and human islets [67]. 


\section{Novel therapeutic approaches in ADPKD targeting glucose metabolism}

\section{Dietary interventions}

\section{Data from animal models}

Warner et al. showed that mild-to-moderate food restriction (10 to $40 \%$ ) could delay the development of cysts in a progressive mouse model of ADPKD [6]. Kipp et al. confirmed that a mild reduction of $23 \%$ in total food intake had a significant inhibitory effect on ADPKD progression in an orthologous mouse model of ADPKD. Reduced food intake was associated with reduced cyst growth and proliferation, a minor reduction in total body weight, reduced mTORC1 activation in mice, as well as preserved kidney function at 7 weeks [5]. Additionally, Kashyap et al. identified a role of IGF pathways in ADPKD pathogenesis. PAPP-A, a component of the IGF pathway that increases the bioavailability of IGF-1, was highly expressed in kidneys of $P K D 1$-deficient mice and also in cystic fluids and kidneys of humans with ADPKD [68, 69]. In this study, PAPP-A deficiency decreased the development of cysts in ADPKD mice, and treatment of mice with a monoclonal antibody that blocks the proteolytic activity of PAPP-A was associated with a decreased cystic burden [68].

Subsequently, Torres et al. analyzed the effect of time-restricted feeding in a non-orthologous rat model of polycystic kidney disease. They found that Harlan Sprague-Dawley (Han:SPRD) rats placed on a timerestricted feeding regimen during 5 weeks show improvement of kidney function and reduced cystogenesis compared to the ad libitum group. The metabolic state of ketosis induced by the time-restricted feeding regimen was responsible for the observed effect of reducing cystogenesis since rats treated with $\beta$-hydroxybutyrate derived from ketosis had reduced cyst growth compared with rats on the control diet [7]. This highlights the apparent inflexibility of ADPKD cells, which are highly glucose-dependent but are not able to metabolize fatty acids and ketones [7].

More recently, Ramalingam and colleagues demonstrated increased levels of methionine and S-adenosylmethionine in ADPKD murine models and showed methionine dietary restriction attenuated cyst growth in these models [70].

\section{Clinical data}

Dietary interventions such as intermittent fasting and ketogenic diet are known to be feasible, inexpensive, and safe, but their success mainly depends on patient adherence. The clinical trial (NCT03342742) assessing the safety and tolerability of daily caloric restriction in overweight and obese adult patients with ADPKD has been recently completed and trial results are pending. The objective was to determine the feasibility of either daily caloric restriction or intermittent fasting for 1 year in 28 overweight/obese adult ADPKD patients with eGFR $\geq 30 \mathrm{ml} / \mathrm{min} / 1.73 \mathrm{~m}^{2}$. As secondary endpoints, changes in kidney growth were assessed for both food restriction and intermittent fasting interventions. Another clinical trial (NCT04907799) is currently ongoing to evaluate the impact of daily caloric restriction in 126 overweight and obese ADPKD adult patients on changes in height-corrected TKV. Two other pilot studies are in the recruiting phase to evaluate the feasibility of two distinct dietary interventions: the pilot study NCT04680780 will evaluate the safety and tolerance of a ketogenic diet for 3 months in 63 ADPKD patients, and study NCT04534985 will focus on the adherence and feasibility of a timerestricted feeding intervention in 30 overweight and obese ADPKD patients (Table 2).

\section{Metformin}

\section{Data from animal models}

Metformin, a well-known activator of the AMPK pathway, has demonstrated conflicting results. It has been effective in reducing cystogenesis in both in vitro and in vivo PKD models [8, 9]. However, no effect of metformin alone or in combination with canagliflozin was observed in an adultonset mouse model of ADPKD, which might be related to the more slowly progressive disease compared to the earlier studies [15].

\section{Clinical data}

Metformin is a very old and safe drug that has long been used as a first-line treatment for type 2 diabetes [71]. Metformin was also found to promote weight loss and is currently used to treat overweight and obese patients with insulin resistance and/or pre-diabetes [72]. Most common adverse events of metformin-based therapy are gastrointestinal side effects, including nausea, abdominal cramps, and diarrhea [73]. Lactate acidosis, a rare but alarming side effect of metformin, mainly occurs in patients with kidney, hepatic, or cardiac insufficiency [73]. In the pediatric population, metformin has been reported to improve insulin sensitivity and weight loss in obese children and adolescents [74]. In a recent pilot study, a low dose of metformin $(850 \mathrm{mg} /$ day) in young children with obesity and risk markers for metabolic syndrome was well tolerated and had a positive 
Table 2 Clinical studies evaluating treatments targeting glucose metabolism

\begin{tabular}{|c|c|c|}
\hline Study & Population/intervention & Findings \\
\hline \multicolumn{3}{|c|}{ Treatment targeting glucose metabolism } \\
\hline Knowler et al. [71] & $\begin{array}{l}\text { Safety and tolerability of metformin in } 97 \text { ADPKD patients } \\
\text { aged } 18 \text { to } 60 \text { years with eGFR }>50 \mathrm{ml} / \mathrm{min} / 1.73 \mathrm{~m}^{2}\end{array}$ & $\begin{array}{l}\text {-No serious adverse events } \\
\text {-Gastrointestinal symptoms similar between both groups } \\
\text {-No significant trends in eGFR slope and HtTKV }\end{array}$ \\
\hline Seifarth et al. [72] & $\begin{array}{l}\text { Safety and tolerability of metformin in } 51 \text { ADPKD patients } \\
\text { aged } 30 \text { to } 60 \text { years with eGFR } 50 \text { to } 80 \mathrm{ml} / \mathrm{min} / 1.73 \mathrm{~m}^{2}\end{array}$ & $\begin{array}{l}\cdot \text { No serious adverse events } \\
\cdot \uparrow \text { gastrointestinal symptoms in the metformin group } \\
\cdot \text { No significant differences in eGFR slope and HtTKV } \\
\text { between both groups }\end{array}$ \\
\hline NCT $04,939,935$ & $\begin{array}{l}\text { Metformin therapy in } 1164 \text { ADPKD patients aged } 18 \text { to } \\
70 \text { years with eGFR } \geq 45 \mathrm{ml} / \mathrm{min} / 1.73 \mathrm{~m}^{2} \text { and }<90 \mathrm{ml} / \\
\mathrm{min} / 1.73 \mathrm{~m}^{2}\end{array}$ & Ongoing \\
\hline NCT $03,342,742$ & $\begin{array}{l}\text { Daily caloric restriction or intermittent fasting for } 1 \text { year in } \\
\text { overweight/obese ADPKD patients with eGFR } \geq 30 \mathrm{ml} / \\
\min / 1.73 \mathrm{~m}^{2}\end{array}$ & Completed \\
\hline NCT 04,907,799 & $\begin{array}{l}\text { Daily caloric restriction over } 2 \text { years in } 126 \text { overweight/obese } \\
\text { ADPKD patients with eGFR } \geq 30 \mathrm{ml} / \mathrm{min} / 1.73 \mathrm{~m}^{2}\end{array}$ & Ongoing \\
\hline NCT $04,680,780$ & $\begin{array}{l}\text { Ketogenic diet for } 3 \text { months in } 21 \text { ADPKD patients from } 18 \text { to } \\
60 \text { years with CKD stages } 1-3\end{array}$ & Ongoing \\
\hline NCT $04,534,985$ & $\begin{array}{l}\text { Adherence, safety, and tolerability of time-restricted feeding } \\
\text { over } 1 \text { year in } 30 \text { ADPKD patients from } 18 \text { to } 65 \text { years with } \\
\text { eGFR } \geq 30 \mathrm{ml} / \mathrm{min} / 1.73 \mathrm{~m}^{2}\end{array}$ & Ongoing \\
\hline
\end{tabular}

$A D P K D$, autosomal dominant polycystic kidney disease; $e G F R$, estimated glomerular filtration rate; $H t T K V$, height-corrected total kidney volume

effect on body composition and inflammatory markers after 12 months [75]. Furthermore, in adolescents with type 1 diabetes, metformin treatment was associated with a significant improvement of insulin resistance and vascular dysfunction [76]. There are short-term studies regarding obesity and metformin in reducing BMI and insulin resistance in children $[77,78]$ but there is still a lack of long-term data regarding metformin in the pediatric population.

Apart from these metabolic effects, a nephroprotective effect of metformin was highlighted in vitro and in vivo [79]. Moreover, observational clinical studies also suggested a beneficial impact of metformin on CKD progression [80]. The RENOMET study (NCT 03,831,464), a randomized controlled double-blind clinical trial to assess the effect of metformin on the progression of kidney failure in nondiabetic adult CKD patients (including ADPKD patients), is currently ongoing.

In the recent TAME study, a 2-year randomized placebocontrolled clinical trial, metformin was reported to be safe and tolerable in adult ADPKD patients (18 to 60 years) with eGFR $\geq 50 \mathrm{ml} / \mathrm{min} / 1.73 \mathrm{~m}^{2}$. Both the eGFR decline and TKV expansion were assessed as secondary endpoints, with no significant reductions in metformin-treated patients compared to controls [10]. This could be explained by the fact that only $35 \%$ of patients have tolerated the maximal dosage of metformin (2000 mg/day). Furthermore, mean eGFR of participants was around $86 \mathrm{ml} / \mathrm{min} / 1.73 \mathrm{~m}^{2}$, suggesting mild disease progression with no observable impact of metformin at this early stage within the study duration [81]. The safety and tolerability of metformin was confirmed in a second prospective randomized controlled study including 51 adult ADPKD patients with preserved kidney function over 12 months of follow-up [11]. Another prospective randomized controlled trial (NCT 04,939,935) to evaluate the safety, tolerability, and effect of metformin therapy on kidney function decline and cyst growth is ongoing (Table 2).

Whether metformin could have a double-positive effect in overweight or obese children with ADPKD remains an open question for future clinical studies.

\section{Sodium-glucose cotransporter inhibition: the gliflozins}

\section{Data from animal models}

Several studies have evaluated the effect of sodium-glucose cotransporter (SGLT) inhibition in murine models of PKD. Dapagliflozin, a selective SGLT2 inhibitor, seems to accelerate cystogenesis in PCK rats [13]. Conversely, dapagliflozin-treated Han:SPRD rats displayed glucosuria, higher creatinine clearance, and decreased albuminuria, with no significant effect on cyst growth [14]. Note that Han:SPRD rats and PCK rats were both spontaneous hereditary models of PKD, but the cysts in Han:SPRD rats mainly originate from the proximal tubule (PT) after missense mutation of the $P k d r l$ gene, while, in PCK rats, cysts mainly originate from 
the collecting duct (as in human ADPKD) following mutation of the Pkhdl gene. The pharmacological inhibition of SGLT2 mainly expressed in the PT may accelerate cystogenesis in PCK rats by increasing the availability of glucose in the distal segments of the nephron. Interestingly, the selective inhibition of both SGLT1 and SGLT2 with phlorizin in Han:SPRD rats was associated with a decreased cystic index and kidney to body weight ratio [12]. In a study using an orthologous mouse model of PKD, canagliflozin, another SGLT2 inhibitor, had no effect on cystic kidney disease [15].

\section{Clinical data}

SGLT inhibitors are of increasing interest in several diseases, including diabetes, CKD, and chronic heart failure. They act as glucose-lowering drugs by inhibiting glucose reabsorption by the renal PTs, resulting in glucosuria, osmotic diuresis, and natriuresis. SGLT2 inhibitors have been approved by the FDA and are widely used as anti-diabetic agents. Apart from a better glycemic control, SGLT2 inhibitors have been shown to reduce cardiovascular events and hospital admissions for heart failure in diabetic patients, as well as improved eGFR slope in both diabetic and nondiabetic patients with CKD [82-84]. Both cardiovascular and nephroprotective effects make SGLT2 inhibitors of particular interest in the field of ADPKD. However, there are currently no data available regarding the potential positive effect of SGLT2 inhibition in patients with ADPKD. Also, no studies have evaluated the potential of SGLT2 inhibitors in the pediatric ADPKD population. Nevertheless, there are several pediatric clinical trials ongoing to evaluate the effect of SGLT2 inhibitors in children with type 1 diabetes (NCT04333823) and obese adolescents with non-alcoholic fatty liver disease condition (NCT03867487). To date, there is still insufficient data regarding the use of SGLT inhibitors in ADPKD.

\section{Conclusion}

The metabolic alterations observed in ADPKD, as well as their impact on ADPKD progression, are mainly derived from in vitro studies, both late-stage and slowly progressive animal models, as well as adult patient sample-based and cohort studies. These findings opened the perspective of novel therapeutic strategies in adult ADPKD. As the emerging data in the field of ADPKD are highlighting the need for early disease stage intervention before the renal parenchyma reaches a "non-return" threshold, managing and targeting altered glucose metabolism in this young population might represent a promising opportunity. Indeed, whether this defective glucose metabolism is an early primary event in ADPKD remains unknown. It is clear that obesity is associated with the development of impaired glucose tolerance, type 2 diabetes, hypertension, and systemic inflammation, which have been suggested as progression markers of ADPKD in the adult population. Since the prevalence of obesity is growing among the pediatric population and is associated with worsening of ADPKD, obese/overweight children with ADPKD represent a specific target population. Lifestyle recommendations, dietary strategies, and pharmacological interventions regarding insulin resistance and obesity might be beneficial in childhood to prevent disease progression and long-term cardiovascular diseases, which are the most important causes of death in patients with ADPKD.

\section{Future perspectives}

Based on our review of the available data on glucose metabolism and its potential role in ADPKD, we can speculate that an impaired glucose metabolism, insulin secretion, or insulin resistance could fuel glucose-dependent metabolic pathways of ADPKD cells and impact ADPKD progression. Even if there are no randomized clinical trials evaluating the impact of lifestyles/dietary interventions on the progression of childhood ADPKD, it is reasonable to suggest that early management of obesity-associated comorbidities could preserve kidney function and decrease the global cardiovascular risk burden of ADPKD patients.

\section{Declarations}

Conflict of interest The authors declare no competing interests.

\section{References}

1. Rowe I, Boletta A (2014) Defective metabolism in polycystic kidney disease: potential for therapy and open questions. Nephrol Dial Transplant 29:1480-1486. https://doi.org/10.1093/ndt/gft521

2. Rowe I, Chiaravalli M, Mannella V, Ulisse V et al (2013) Defective glucose metabolism in polycystic kidney disease identifies a new therapeutic strategy. Nat Med 19:488-493. https://doi.org/10. 1038/nm.3092

3. Nowak KL, Hopp K (2020) Metabolic reprogramming in autosomal dominant polycystic kidney disease evidence and therapeutic potential. Clin J Am Soc Nephrol 15:577-584. https://doi.org/10. 2215/CJN.13291019

4. Podrini C, Rowe I, Pagliarini R, Costa ASH et al (2018) Dissection of metabolic reprogramming in polycystic kidney disease reveals coordinated rewiring of bioenergetic pathways. Commun Biol 1:194. https://doi.org/10.1038/s42003-018-0200-X

5. Kipp KR, Rezaei M, Lin L, Dewey EC, Weimbs T (2016) A mild reduction of food intake slows disease progression in an orthologous mouse model of polycystic kidney disease. Am J Physiol Physiol 310:F726-F731. https://doi.org/10.1152/ajprenal.00551. 2015 
6. Warner G, Hein KZ, Nin V, Edwards M et al (2016) Food restriction ameliorates the development of polycystic kidney disease. J Am Soc Nephrol 27:1437-1447. https://doi.org/10.1681/ASN. 2015020132

7. Torres JA, Kruger SL, Broderick C, Amarlkhagva T et al (2019) Ketosis ameliorates renal cyst growth in polycystic kidney disease. Cell Metab 30:1007-1023. https://doi.org/10.1016/j.cmet.2019. 09.012

8. Takiar V, Nishio S, Seo-Mayer P, King JD Jr et al (2011) Activating AMP-activated protein kinase (AMPK) slows renal cystogenesis. Proc Natl Acad Sci U S A 108:2462-2467. https://doi.org/ 10.1073/pnas.1011498108

9. Chang MY, Ma TL, Hung CC, Tian YC et al (2017) Metformin inhibits cyst formation in a zebrafish model of polycystin-2 deficiency. Sci Rep 7:7161. https://doi.org/10.1038/ s41598-017-07300-x

10. Perrone RD, Abebe KZ, Watnick T, Althouse AD et al (2021) Primary results of the randomized trial of metformin administration in polycystic kidney disease (TAME PKD). Kidney Int 100:684-696. https://doi.org/10.1016/j.kint.2021.06.013

11. Brosnahan GM, Wang W, Gitomer B, Struemph T et al (2021) Metformin therapy in autosomal dominant polycystic kidney disease: a feasibility study. Am J Kidney Dis 12:S02726386(21)00790-3. https://doi.org/10.1053/j.ajkd.2021.06.026

12. Wang X, Zhang S, Liu Y, Spichtig D et al (2013) Targeting of sodium-glucose cotransporters with phlorizin inhibits polycystic kidney disease progression in Han:SPRD rats. Kidney Int 84:962968. https://doi.org/10.1038/ki.2013.199

13. Kapoor S, Rodriguez D, Riwanto M, Edenhofer I et al (2015) Effect of sodium-glucose cotransport inhibition on polycystic kidney disease progression in PCK rats. PLoS ONE 10:e0125603. https://doi.org/10.1371/journal.pone.0125603

14. Rodriguez D, Kapoor S, Edenhofer I, Segerer S et al (2015) Inhibition of sodium-glucose cotransporter 2 with dapagliflozin in Han: SPRD rats with polycystic kidney disease. Kidney Blood Press Res 40:638-647. https://doi.org/10.1159/000368540

15. Leonhard WN, Song X, Kanhai AA, Iliuta IA et al (2019) Salsalate, but not metformin or canagliflozin, slows kidney cyst growth in an adult-onset mouse model of polycystic kidney disease. EBioMedicine 47:436-445. https://doi.org/10.1016/j.ebiom. 2019.08.041

16. Fliszkiewicz M, Niemczyk M, Kulesza A, Łabuś A, Pączek L (2019) Glucose and lipid metabolism abnormalities among patients with autosomal dominant polycystic kidney disease. Kidney Blood Press Res 44:1416-1422. https://doi.org/10.1159/ 000503423

17. Pietrzak-Nowacka M, Safranow K, Byra E, Nowosiad M, Marchelek-Myśliwiec M, Ciechanowski K (2010) Glucose metabolism parameters during an oral glucose tolerance test in patients with autosomal dominant polycystic kidney disease. Scand J Clin Lab Invest 70:561-567. https://doi.org/10.3109/00365513.2010. 527012

18. Nowak KL, You Z, Gitomer B, Brosnahan G et al (2018) Overweight and obesity are predictors of progression in early autosomal dominant polycystic kidney disease. J Am Soc Nephrol 29:571-578. https://doi.org/10.1681/ASN.2017070819

19. Baliga MM, Klawitter J, Christians U, Hopp K et al (2021) Metabolic profiling in children and young adults with autosomal dominant polycystic kidney disease. Sci Rep 11:6629. https://doi.org/ 10.1038/s41598-021-84609-8

20. Yun H-R, Kim H, Park JT, Chang TI et al (2018) Obesity, metabolic abnormality, and progression of CKD. Am J Kidney Dis 72:400-410. https://doi.org/10.1053/j.ajkd.2018.02.362

21. Spoto B, Pisano A, Zoccali C (2016) Insulin resistance in chronic kidney disease: a systematic review. Am J Physiol Renal Physiol 311:F1087-F1108. https://doi.org/10.1152/ajprenal.00340.2016
22. Lalan S, Jiang S, Ng DK, Kupferman F et al (2018) Cardiometabolic risk factors, metabolic syndrome, and chronic kidney disease progression in children. J Pediatr 202:163-170. https://doi.org/10. 1016/j.jpeds.2018.06.007

23. Foster MC, Hwang S-J, Larson MG, Lichtman JH et al (2008) Overweight, obesity, and the development of stage 3 CKD: the Framingham heart study. Am J kidney Dis 52:39-48. https://doi. org/10.1053/j.ajkd.2008.03.003

24. Spinelli A, Buoncristiano M, Kovacs VA, Yngve A et al (2019) Prevalence of severe obesity among primary school children in 21 European countries. Obes Facts 12:244-258. https://doi.org/ $10.1159 / 000500436$

25. Sorof JM, Poffenbarger T, Franco K, Bernard L et al (2002) Isolated systolic hypertension, obesity, and hyperkinetic hemodynamic states in children. J Pediatr 140:660-666. https://doi.org/ 10.1067/mpd.2002.125228

26. Sinha R, Fisch G, Teague B, Tamborlane WV et al (2002) Prevalence of impaired glucose tolerance among children and adolescents with marked obesity. N Engl J Med 346:802-810. https:// doi.org/10.1056/NEJMoa012578

27. Shaw J (2007) Epidemiology of childhood type 2 diabetes and obesity. Pediatr Diabetes 8(Suppl 9):7-15. https://doi.org/10. 1111/j.1399-5448.2007.00329.x

28. Skinner AC, Perrin EM, Moss LA, Skelton JA (2015) Cardiometabolic risks and severity of obesity in children and young adults. $\mathrm{N}$ Engl J Med 373:1307-1317. https://doi.org/10.1056/NEJMoa1502 821

29. Baker JL, Olsen LW, Sørensen TIA (2007) Childhood body-mass index and the risk of coronary heart disease in adulthood. $\mathrm{N}$ Engl J Med 357:2329-2337. https://doi.org/10.1056/NEJMoa072515

30. Wilson PWF, D'Agostino RB, Sullivan L, Parise H, Kannel WB (2002) Overweight and obesity as determinants of cardiovascular risk: the Framingham experience. Arch Intern Med 162:18671872. https://doi.org/10.1001/archinte.162.16.1867

31. Yajnik CS, Katre PA, Joshi SM, Kumaran K et al (2015) Higher glucose, insulin and insulin resistance (HOMA-IR) in childhood predict adverse cardiovascular risk in early adulthood: the Pune children's study. Diabetologia 58:1626-1636. https://doi.org/10. 1007/s00125-015-3602-z

32. Nowak KL, Steele C, Gitomer B, Wang W et al (2021) Overweight and obesity and progression of ADPKD. Clin J Am Soc Nephrol 16:908-915. https://doi.org/10.2215/CJN.16871020

33. Vareesangthip K, Tong P, Wilkinson R, Thomas TH (1997) Insulin resistance in adult polycystic kidney disease. Kidney Int 52:503-508. https://doi.org/10.1038/ki.1997.360

34. Fliser D, Pacini G, Engelleiter R, Kautzky-Willer A et al (1998) Insulin resistance and hyperinsulinemia are already present in patients with incipient renal disease. Kidney Int 53:1343-1347. https://doi.org/10.1046/j.1523-1755.1998.00898.x

35. Turkmen K, Tufan F, Selçuk E, Akpınar T, Oflaz H, Ecder T (2013) Neutrophil-to-lymphocyte ratio, insulin resistance, and endothelial dysfunction in patients with autosomal dominant polycystic kidney disease. Indian J Nephrol 23:34-40. https://doi.org/ 10.4103/0971-4065.107195

36. Menon V, Rudym D, Chandra P, Miskulin D, Perrone R, Sarnak $M$ (2011) Inflammation, oxidative stress, and insulin resistance in polycystic kidney disease. Clin J Am Soc Nephrol 6:7-13. https:// doi.org/10.2215/CJN.04140510

37. DeFronzo RA, Tobin JD, Andres R (1979) Glucose clamp technique: a method for quantifying insulin secretion and resistance. Am J Physiol Endocrinol Metab Gastrointest Physiol 6:E214. https://doi.org/10.1152/ajpendo.1979.237.3.e214

38. Hamer RA, Chow CL, Ong ACM, McKane WS (2007) Polycystic kidney disease is a risk factor for new-onset diabetes after transplantation. Transplantation 83:36-40. https://doi.org/10.1097/01. tp.0000248759.37146.3d 
39. Caillard S, Eprinchard L, Perrin P, Braun L et al (2011) Incidence and risk factors of glucose metabolism disorders in kidney transplant recipients: role of systematic screening by oral glucose tolerance test. Transplantation 91:757-764. https://doi.org/10.1097/TP. ob013e31820f0877

40. de Mattos AM, Olyaei AJ, Prather JC, Golconda MS et al (2005) Autosomal-dominant polycystic kidney disease as a risk factor for diabetes mellitus following renal transplantation. Kidney Int 67:714-720. https://doi.org/10.1111/j.1523-1755.2005.67132.x

41. Reed B, Helal I, McFann K, Wang W et al (2011) The impact of type II diabetes mellitus in patients with autosomal dominant polycystic kidney disease. Nephrol Dial Transplant 27:2862-2865. https://doi.org/10.1093/ndt/gfr744

42. Kuo IY, Chapman AB (2020) Polycystins, ADPKD, and cardiovascular disease. Kidney Int reports 5:396-406. https://doi.org/ 10.1016/j.ekir.2019.12.007

43. Major RW, Cheng MRI, Grant RA, Shantikumar S et al (2018) Cardiovascular disease risk factors in chronic kidney disease: a systematic review and meta-analysis. PLoS ONE 13:e0192895. https://doi.org/10.1371/journal.pone.0192895

44. Sans L, Pascual J, Radosevic A, Quintian C et al (2016) Renal volume and cardiovascular risk assessment in normotensive autosomal dominant polycystic kidney disease patients. Medicine (Baltimore) 95:e5595. https://doi.org/10.1097/MD.0000000000 005595

45. Lai S, Mastroluca D, Matino S, Panebianco V et al (2017) Early markers of cardiovascular risk in autosomal dominant polycystic kidney disease. Kidney Blood Press Res 42:1290-1302. https:// doi.org/10.1159/000486011

46. Gorriz JL, Arroyo D, D'Marco L, Torra R et al (2021) Cardiovascular risk factors and the impact on prognosis in patients with chronic kidney disease secondary to autosomal dominant polycystic kidney disease. BMC Nephrol 22:110. https://doi.org/10.1186/ s12882-021-02313-1

47. Nowak KL, Murray K, You Z, Gitomer B et al (2021) Pain and obesity in autosomal dominant polycystic kidney disease: a post hoc analysis of the halt progression of polycystic kidney disease (HALT-PKD) studies. Kidney Med 3:536-545.e1. https://doi.org/ 10.1016/j.xkme.2021.03.004

48. Bajwa ZH, Gupta S, Warfield CA, Steinman TI (2001) Pain management in polycystic kidney disease. Kidney Int 60:1631-1644. https://doi.org/10.1046/j.1523-1755.2001.00985.x

49. World Health Organization (2017) Tenfold increase in childhood and adolescent obesity in four decades: new study by Imperial College London and WHO. In: Available online. https://www. who.int/news/item/11-10-2017-. Accessed 3 Jun 2021

50. Franks PW, Hanson RL, Knowler WC, Sievers ML et al (2010) Childhood obesity, other cardiovascular risk factors, and premature death. N Engl J Med 362:485-493. https://doi.org/10.1056/ NEJMoa0904130

51. Whaley-Connell A, Sowers JR (2017) Insulin resistance in kidney disease: is there a distinct role separate from that of diabetes or obesity? Cardiorenal Med 8:41-49. https://doi.org/10.1159/00047 9801

52. Helal I, Reed B, Mcfann K, Yan XD et al (2011) Glomerular hyperfiltration and renal progression in children with autosomal dominant polycystic kidney disease. Clin J Am Soc Nephrol 6:2439-2443. https://doi.org/10.2215/CJN.01010211

53. Chagnac A, Weinstein T, Korzets A, Ramadan E et al (2000) Glomerular hemodynamics in severe obesity. Am J Physiol Renal Physiol 278:F817-822. https://doi.org/10.1152/ajprenal.2000. 278.5.F817

54. Kahveci AS, Barnatan TT, Kahveci A, Adrian AE et al (2020) Oxidative stress and mitochondrial abnormalities contribute to decreased endothelial nitric oxide synthase expression and renal disease progression in early experimental polycystic kidney disease. Int J Mol Sci 21:1994. https://doi.org/10.3390/ijms2 1061994

55. Murphy MO, Huang H, Bauer JA, Schadler A et al (2021) Impact of pediatric obesity on diurnal blood pressure assessment and cardiovascular risk markers. Front Pediatr 9:123. https://doi.org/10.3389/fped.2021.596142

56. Litwin M, Kułaga Z (2021) Obesity, metabolic syndrome, and primary hypertension. Pediatr Nephrol 36:825-837. https://doi. org/10.1007/s00467-020-04579-3

57. Marlais M, Cuthell O, Langan D, Dudley J et al (2016) Hypertension in autosomal dominant polycystic kidney disease: a meta-analysis. Arch Dis Child 101:1142-1147. https://doi.org/ 10.1136/archdischild-2015-310221

58. Massella L, Mekahli D, Paripović D, Prikhodina L et al (2018) Prevalence of hypertension in children with early-stage ADPKD. Clin J Am Soc Nephrol 13:874-883. https://doi.org/ 10.2215/CJN.11401017

59. Fick-Brosnahan GM, Tran ZV, Johnson AM, Strain JD, Gabow PA (2001) Progression of autosomal-dominant polycystic kidney disease in children. Kidney Int 59:1654-1662. https://doi. org/10.1046/j.1523-1755.2001.0590051654.x

60. Cadnapaphornchai MA, McFann K, Strain JD, Masoumi A, Schrier RW (2008) Increased left ventricular mass in children with autosomal dominant polycystic kidney disease and borderline hypertension. Kidney Int 74:1192-1196. https://doi.org/10. 1038/ki.2008.397

61. Mastrangelo A, Martos-Moreno GÁ, García A, Barrios V et al (2016) Insulin resistance in prepubertal obese children correlates with sex-dependent early onset metabolomic alterations. Int J Obes (Lond) 40:1494-1502. https://doi.org/10.1038/ijo. 2016.92

62. Kwaifa IK, Bahari H, Yong YK, Noor SM (2020) Endothelial dysfunction in obesity-induced inflammation: molecular mechanisms and clinical implications. Biomolecules 10:291. https://doi.org/10. 3390/biom 10020291

63. Chiaravalli M, Rowe I, Mannella V, Quilici G et al (2016) 2-Deoxy-D-glucose ameliorates PKD progression. J Am Soc Nephrol 27:1958-1969. https://doi.org/10.1681/ASN.2015030231

64. Riwanto M, Kapoor S, Rodriguez D, Edenhofer I et al (2016) Inhibition of aerobic glycolysis attenuates disease progression in polycystic kidney disease. PLoS ONE 11:e0146654. https://doi. org/10.1371/journal.pone.0146654

65. Grahammer F, Ramakrishnan SK, Rinschen MM, Larionov AA et al (2017) mTOR regulates endocytosis and nutrient transport in proximal tubular cells. J Am Soc Nephrol 28:230-241. https:// doi.org/10.1681/ASN.2015111224

66. Zhang H, Kong W-J, Shan Y-Q, Song D-Q et al (2010) Protein kinase $\mathrm{D}$ activation stimulates the transcription of the insulin receptor gene. Mol Cell Endocrinol 330:25-32. https://doi.org/ 10.1016/j.mce.2010.07.022

67. Khan S, Ferdaoussi M, Bautista A, Bergeron V et al (2019) A role for PKD1 in insulin secretion downstream of P2Y1 receptor activation in mouse and human islets. Physiol Rep 7:e14250. https:// doi.org/10.14814/phy2.14250

68. Kashyap S, Hein KZ, Chini CC, Lika J et al (2020) Metalloproteinase PAPP - a regulation of IGF-1 contributes to polycystic kidney disease pathogenesis. JCI Insight 5:e135700. https://doi. org/10.1172/jci.insight. 135700

69. Kashyap S, Zeidler JD, Chini CCS, Chini EN (2020) Implications of the PAPP-A-IGFBP-IGF-1 pathway in the pathogenesis and treatment of polycystic kidney disease. Cell Signal 73:109698. https://doi.org/10.1016/j.cellsig.2020.109698

70. Ramalingam H, Kashyap S, Cobo-Stark P, Flaten A et al (2021) A methionine-Mettl3-N6-methyladenosine axis promotes polycystic kidney disease. Cell Metab 33:1234-1247.e7. https://doi.org/10. 1016/j.cmet.2021.03.024 
71. Knowler WC, Barrett-Connor E, Fowler SE, Hamman RF et al (2002) Reduction in the incidence of type 2 diabetes with lifestyle intervention or metformin. N Engl J Med 346:393-403. https:// doi.org/10.1056/NEJMoa012512

72. Seifarth C, Schehler B, Schneider HJ (2013) Effectiveness of metformin on weight loss in non-diabetic individuals with obesity. Exp Clin Endocrinol Diabetes 121:27-31. https://doi.org/10. 1055/s-0032-1327734

73. Soliman A, DeSanctis V, Alaaraj N, Hamed N (2020) The clinical application of metformin in children and adolescents: a short update. Acta Biomed 91:e2020086. https://doi.org/10.23750/abm. v91i3.10127

74. Masarwa R, Brunetti VC, Aloe S, Henderson M, Platt RW, Filion KB (2021) Efficacy and safety of metformin for obesity: a systematic review. Pediatrics 147:e20201610. https://doi.org/10.1542/ peds. $2020-1610$

75. Bassols J, Martínez-Calcerrada J-M, Osiniri I, Díaz-Roldán F et al (2019) Effects of metformin administration on endocrinemetabolic parameters, visceral adiposity and cardiovascular risk factors in children with obesity and risk markers for metabolic syndrome: a pilot study. PLoS ONE 14:e0226303. https://doi.org/ 10.1371/journal.pone.0226303

76. Bjornstad P, Schäfer M, Truong U, Cree-Green M et al (2018) Metformin improves insulin sensitivity and vascular health in youth with type 1 diabetes mellitus. Circulation 138:2895-2907. https://doi.org/10.1161/CIRCULATIONAHA.118.035525

77. Park MH, Kinra S, Ward KJ, White B, Viner RM (2009) Metformin for obesity in children and adolescents: a systematic review. Diabetes Care 32:1743-1745. https://doi.org/10.2337/ dc09-0258
78. Kendall D, Vail A, Amin R, Barrett T et al (2013) Metformin in obese children and adolescents: the MOCA trial. J Clin Endocrinol Metab 98:322-329. https://doi.org/10.1210/jc.2012-2710

79. De Broe ME, Jouret F (2020) Does metformin do more benefit or harm in chronic kidney disease patients? Kidney Int 98:10981101. https://doi.org/10.1016/j.kint.2020.04.059

80. Crowley MJ, Diamantidis CJ, McDuffie JR, Cameron CB et al (2017) Clinical outcomes of metformin use in populations with chronic kidney disease, congestive heart failure, or chronic liver disease: a systematic review. Ann Intern Med 166:191-200. https://doi.org/10.7326/M16-1901

81. Ong ACM, Gansevoort RT (2021) TAMEing ADPKD with metformin: safe and effective? Kidney Int 100:513-515. https://doi. org/10.1016/j.kint.2021.07.021

82. Heerspink HJL, Kosiborod M, Inzucchi SE, Cherney DZI (2018) Renoprotective effects of sodium-glucose cotransporter-2 inhibitors. Kidney Int 94:26-39. https://doi.org/10.1016/j.kint.2017.12. 027

83. Perkovic V, Jardine MJ, Neal B, Bompoint S et al (2019) Canagliflozin and renal outcomes in type 2 diabetes and nephropathy. N Engl J Med 380:2295-2306. https://doi.org/10.1056/NEJMo a1811744

84. Levin A, Perkovic V, Wheeler DC, Hantel S et al (2020) Empagliflozin and cardiovascular and kidney outcomes across KDIGO risk categories: post hoc analysis of a randomized, double-blind, placebo-controlled, multinational trial. Clin J Am Soc Nephrol 15:1433-1444. https://doi.org/10.2215/CJN.14901219

Publisher's note Springer Nature remains neutral with regard to jurisdictional claims in published maps and institutional affiliations. 